\title{
Can we afford to wait any longer? Pre-school children are ready to learn mathematics
}

\begin{abstract}
South African students' poor mathematics performance on national and international tests can be attributed to the gap the children begin schooling with from different socio economics homes. Wright et al assert that this gap continues to grow the longer students are in school. Early childhood research highlights the significant educational gains of exposing young children to quality, structured mathematical play or activity that goes beyond what is learned within the family and community. South Africa has high levels of poverty and inequality and also has tremendous difficulties in overcoming these inequalities. Most provision of quality pre-school education is private, self-funded and not targeted to poor children resulting to different levels of mathematics readiness prior entry to primary school. This paper argues for quality mathematics interventions, longitudinal studies on impact of such interventions and tracking studies on schooling effects of early quality mathematics preparation, higher education effects, and labour market effects.
\end{abstract}

Keywords: Inequity, innate abilities, play-based, early childhood, mathematics

Nosisi Nellie Feza, Human Sciences Research Council, Education and Skills Department. E-mail:nfeza@hsrc.ac.za 


\section{Introduction}

Herein lies a danger. If children from different socioeconomic and cultural backgrounds enter elementary school at notably different levels of readiness in school mathematics, the nations with relatively well-prepared children will be better able to meet high expectations and a rapid instructional pace in K-12 mathematics than nations with relatively less-prepared children. Thus, the accommodation of raised expectations will need to occur at the prekindergarten level as well (Starkey et al, 2004, p.117).

Poor mathematics performance of South African students in national and international tests has been investigated. Research on mathematical instruction revealed poor content knowledge of teachers and lack of relevant instruction (Adler, 2001; Mji and Makgato, 2006; van der Sandt and Niewoudt, 2003). Also, studies on factors that impede mathematics conceptualisation indicated that learning mathematics in a language that is not a student first language create complex processes, (Adler, 2001) Such challenges lead to code-switching that teachers are ashamed of (Setati \& Adler, 2001 ) Little is known about the early exposure to mathematics stimulation. This paper supports Starkey et al (2004) in encouraging mathematics play at the pre-school level. Starkey et al (2004) highlight that the learning of mathematics depends on structured exposure to mathematical concepts in pre-school years. Likewise Bowman, Donovan \& Burns (2001); and Denton \& West (2002) indicated that in the United Kingdom children from low socio economic backgrounds and minority-languages demonstrated lower levels of mathematics knowledge than their more advantaged peers, who assumedly have more exposure. This difference has been proven to increase over time (Denton and West, 2002; Wright, Martland \& Stafford, 2000). Hence studies were conducted on interventions that were intended to close the gap between the levels of mathematics knowledge of children from low socio economic backgrounds and children from higher socio economic background (Becker and Luther, 2002; Judge, Puckett and Bell, 2006).

In the South African literature studies on mathematical exposure of young children from low socio economic pre-school has proven that interventions yield to improved numeracy skills and teacher-child interaction (Hoppenbrouwer, 2011). Hutchinson and Pournara (2011) revealed that children who were four and half year old and above from middle and upper socio economic ECD centres were able to copy extended patterns with more focus on colour than objects used at different developmental levels. Little is known about the quality of mathematics young children from 0 to 4 are exposed and the levels of understanding possessed by practitioners of young children about learning and teaching of mathematics. In this article I argue that such evidence about young children in middle and higher socio-economic ECD centres and also such interventions are one way of contributing to our understanding of early mathematics concept development and the role of pre-school education. However, there is a need for quality mathematics interventions that will bring forth the understandings of preschool practitioners of children's learning and teaching of mathematics and a need for longitudinal studies that will assist in raising awareness to the parents, private sector and government of the importance of ECD mathematics as Biersteker and 
Dawes (2008) and Richter et al (2012) suggested in addressing the varied quality of ECD provision.

\section{Current status of ECD provisioning}

South Africa is a country with high levels of poverty and inequality (Penn, 2008) and faces tremendous difficulties in overcoming these inequalities. For this reason, the Minister of Education called for a pause in participating in the TIMSS after 2003 and until 2011 with the hope of addressing some of the inequalities concerning mathematics and science education.

Furthermore, an integrated plan (2005-2010) for 0-4 year children that brings together department of health, social development and education was formulated. Some of the issues the plan aimed to address were "the uncoordinated service delivery, limited access to services, inequities in existing ECD provisioning, and variable quality of ECD services" (UNICEF, 2005; p.5). The national integrated plan (NIP) for ECD aimed "to create an environment where children can grow, thrive and be able to be better prepared for their future roles and responsibilities in society" (UNICEF, 2005; p.7). The implementation of this goal according to the plan was guided "by principles of excellence, access, equity, diversity and accountability and communitydriven provision' (p.11). Biesterker \& Dawes (2008) evaluated ECD programmes of Brazil and Philippine with an objective to inform the up scaling of ECD in South Africa. Their summary report suggested that South Africa through legislation of free health care made a significant coverage therefore, using health system as a vehicle on parenting education and more services have potential to expand ECD services like in the other two countries. They also highlighted the disadvantage of not having clear roles that the equally responsible departments play in ECD: the Department of Social Development (DoSD), the Department of Education (DoE), the Office of the Rights of the Child (ORC) impedes realization of the NIP. Also localizing ECD delivery on municipal level was suggested however this kind of delivery requires competency, a challenge in the South African context that will need capacity building. A significant factor learnt from the United States and United Kingdom is informing parents, private sector and government about the importance of ECD.

The current status of ECD in South Africa is presented by the diagnostic review that was commissioned by the Department of Performance Monitoring and Evaluation in the Presidency and the Inter- Departmental Steering Committee on ECD. The review highlighted a lot of improvement that the South African government has achieved regarding services needed by children since 1994 in terms of access to safe water, access to electricity, access to clinics, prevention of HIV AIDS transmission from mom to child, increased immunization, increased birth registrations, increased eligibility of child support Grant and increased enrolments to Grade R (Richter et al., 2012). The review highlights the disconnectedness of the departments that are responsible for ECD as reasons for gaps in service because of the lack of a joint goal a concern that was previously raised by Biersteker and Dawes. According to Richter et al. (2012) the 
isolated pockets of delivery results to discrepancies in services provided. The review indicate that the funding is skewed towards older children leaving children ( 0 - 2 years) without needed help due to the assumption that family is an appropriate provider of care in a way ignoring the socio economic gaps of the South African community Richter et al (2012). On the other hand the enrolment for 3-4 year olds depends on availability of ECD centres in their communities and availability of fees from home to pay for the service. For poor families access is denied and hindering the realization of the NIP while for some ECD centres resources are limited hampering high quality service. Therefore, the review indicates the varied quality of ECD services provided (Righter et al. (2012). Such service cannot address the inequity challenges the system has in education as research has proven the impact quality pre-school has on future learning and labour market. This opens up a role research has to play for cognitive development of the child. Research has a role to play in informing curriculum development of young children's mathematics, in informing the professionalization of ECD practitioners on developmental needs of practitioners on how to expose young children in mathematical developmental appropriate activities with a purpose, in informing the South African community about the importance of quality mathematics exposure for young children in building human capacity.

\section{Knowledge of mathematics learning}

I hope that the day will come when teachers entering the classroom and those already in the classroom have as much scientific knowledge about how children learn mathematics as physicians have about the causes of illnesses (Kamii, 2011)

Kamii's NCTM statement supports the argument of this paper on calling for interventions that will highlight the practitioners' competencies on how children learn mathematics and develop them, also how to assess children's levels of thinking to inform practice. Research has indicated that quality pre-school mathematics predicts future success in future learning experiences regardless of socio economic background. Currently, South Africa needs confidence boost from students' mathematics performance in the Trends in International Mathematics and Science Study (TIMSS), the Southern and Eastern Africa Consortium for Monitoring Educational Quality (SACMEQ) and the Annual National Assessments (ANAs). Sylva et al (2004) and Siraj-Blatchford et al (2002) confirmed that through quality mathematics interventions policy and curriculum development in the United Kingdom was influenced. In addition early childhood practitioners became acquainted with observing, scaffolding children's learning, extending children's thinking through questioning, learning through play, balanced between child-initiated and adult-initiated activity, and between individual and group work with new curricula that is "play-based" and "child centred" (Slovin \& Veneciano, 2008; Brooker, 2011,p. 139).

The United States research on how to develop young children's numeracy concepts lead to interventions and curricula for early childhood mathematics (Kamii, 2000; Clements, 2001; Young-Loveridge, 2004). Interventions that proved to have gains for all children encouraged scaffolding of mathematics learning, small group work 
for individualism, planned activities, informal mathematics experiences, developing mathematics from children's spontaneous activity, focusing on children's interests and play situations, connecting children's informal knowledge to formal mathematics, and making the purpose of mathematical learning unambiguous (Clements and Sarama, 2007; Starkey et al, 2004; Clements and Sarama, 2004; Ginsburg et al, 2006; Clements and Stephen, 2004; Clements et al, 2004).

\section{Pedagogical support of young children in learning mathematics}

In understanding how children learn and can be taught mathematics prior to entering formal education, Lee and Ginsburg (2009) discuss nine misconceptions about "learning and teaching mathematics for young children" (p.37). Those misconceptions are:

- Young children are not ready for mathematics education

- Mathematics is for some bright kids with mathematics

- $\quad$ Simple numbers and shapes are enough

- $\quad$ Language and literacy are more important than mathematics

- Teachers should provide an enriched physical environment, step back, and let the children play

- Mathematics should not be taught as stand-alone subject matter

- Assessment in mathematics is irrelevant when it comes to young children

- Children learn mathematics only by interacting with concrete objects

- Computers are inappropriate in teaching and learning mathematics

Some of the misconceptions Lee and Ginsburg listed originate from misinterpretation of the two ancestral theories of cognition: the Piagetian and the Vygotskian, more especially the Piagetian theory.

\section{Piagetian Perspective}

Jean Piaget's theory of constructivism established that children construct knowledge through experiencing the world actively. DeVries and Sales (2011, 11) extend the meaning of construction to "creation, testing, refining of original thoughts", impulsive ideas about how things work. According to Piaget (1964) and Piaget and Inhelder (1969) this active experimentation for young children is about physical knowledge. In constructing knowledge young children connects relations between objects mentally (DeVries and Sales, 2011). For example when children play with shapes they begin to make relations between a square and a triangle and begin to talk about "look like a box" and "look like a roof of the house" (Van Hiele, 1986). This description comes from connecting previously experienced observations to the new ones. Hence, Kamii and DeClark (1985) argue that educators need to understand the concept of autonomy 
as the aim of education Piaget advocated. Kamii and DeClark see this need as of crucial importance for educators if they are to create conducive classroom environment for learning so that children will be able to have these experiences that involves their physical world. Autonomy is described by Kamii and DeClark $(1985,40)$ "being governed by one self". She discusses the moral and intellectual aspects of autonomy. Moral autonomy advocates for nurturing of independent responsible decision makers without depending to gaining rewards (Kamii and DeClark, 1985). Children should be able to independently choose the right actions from wrong. Intellectual autonomy refers the connection of the relationships in the physical world that leads to children questioning things that do not connect. For example Kamii \& DeClark (1985) refers to the belief in Santa Claus when a six year old girl one day asked her mom the following questions: "How come Santa Claus uses the same wrapping paper as we do?" (p.45). Her mom's response was satisfactory for that moment but as time goes her next question was "How Come Santa Clause has the same handwriting as Daddy?" (p.45). This example indicate that the child has her own thoughts about Santa and started connecting her experiences and observations together and started figuring out that something was strange about Santa and them. First it was similar wrapping papers and now Daddy's hand writing is the same as Santa. Then the next question will be, "Is there Santa Claus?" Has Daddy been Santa all this time? The child's autonomous thought do not match what the child has been taught. As educators Kamii and DeClark advocates that encouraging autonomy in children's mind will enrich their thinking capabilities however, controlling their creation, and experiences impede their development.

\section{Vygotskian Perspective}

The sociocultural theory of Vygotsky asserts that all children have potential for learning. Kozulin (2003) highlights three important elements of sociocultural theory. He argues that this theory addresses multiculturalism, mediation and learning potential. In describing multiculturalism Kozulin (2003) support the notion of diverse ways of knowing by bringing in the notion of psychological tools. Psychological tools in Vygotskian perspective are symbolic artifacts (Kozulin, 2003). These symbolic artifacts originate from all cultures. Each culture has its own symbolic artifacts that children internalize and use them to master or learn new ideas. One of these artifacts is literacy that children attain from home through observations, listening to adults and other children etc. This literacy when internalized by children it becomes their psychological tool that assist their psychological function of perspective, memory and attention (Kozulin, 2003). Activities that parents and the environment expose to children's mathematical development support the development of psychological tools children need. Starkey and Klein (2007) compared the sociocultural influence of American children in their mathematical development with the Chinese and Japanese children. In their results Chinese and Japanese children enter preschool with superior mathematical performance than American children. In explaining this discrepancy Starkey and Klein (2008) discovered that the early environment children experience 
influences their mathematical performance prior entering preschool. In Vygotskian terms the Chinese and Japanese culture expose children to different experiences that develop their psychological tools to a superior level. Investigating these experiences Starkey and Klein (2007) assert that Asian literacy develop number sense better than English, also Asian mothers teach their children to count to high numbers (White, 1987). Thus, certify the role of different symbolic artifacts children experience in their development. Donato and Maccormick (1994) describe mediation as a tool of cognitive change. In their perspective mediation takes place in many forms. Sometimes it can take the form of the textbook, manipulatives, classroom discourse, interaction with peers, direct instruction from the teacher. Mediation is intertwined within the context of sociocultural processes. Learning potential is referred to as part of the zone of proximal development (ZPD) (Chaiklin, 2003). The ZPD is described as the child's actual performance and learning potential (Vygotsky, 1978). Kozulin $(2003,17)$ describes the ZPD as a level that informs educators about (1) 'psychological functions of the child emerging at a particular moment, not fully developed (2) the assisted performance that could be used as a legitimate parameter of assessment procedure (3) how to conceptualize the difference between the level of the child's actual performance and learning potential.

\section{Young children's mathematical innate abilities}

Cognitive developmental psychologists have shown that young children have some number concept as early as six months old. For example, Hyde and Spelke (2010) found that (6-7 months) old children possess two developing systems of non-verbal numerical cognition: one that responds to small quantities as individual objects and the other that responds to large quantities as approximate numerical value. These results provide evidence of the existence of these numerical intuitions that had been proven to become active in learning to count (Condry and Spelke, 2008). Furthermore, a study of 5 to 7 year old children who received no formal schooling revealed that the students had intuitive multipliable abilities they possessed innately (McCrink, and Spelke, 2010). Also, five year old children solved arithmetic problems accurately in a pre-school investigation that was assessing the understanding of the inverse relationship between addition and subtraction (Gilmore and Spelke, 2007).

In addition, young children do not only show innate numerical abilities, they also demonstrate spatial reasoning abilities. Clements et al. (1997) highlighted the importance of developing geometric knowledge and spatial sense at an early age. Freudenthall (1973) states that; "Geometry is grasping space. And since it is about the education of children, it is grasping that space in which the child lives, breathes, and moves. The space that the child must learn to know, explore, and conquer, in order to live, breath and move better in it. Are we so accustomed to this space that we cannot imagine how important it is for us and for those we are educating?" (p. 403). Geometric reasoning has been proven to emerge early as Lu (2001) mentions that the crawling of young children provides them opportunities to understand space. "As children learn language and other symbol systems, they begin to combine their 
core numerical and geometrical representations productively, in uniquely human ways. These combinations may give rise to the first truly abstract concepts at the foundations of mathematics" (Spelke, 2011, 287). Navigation skills demonstrated by animals are proved to be innate in humans too in understanding space (Wang \& Spelke, 2002). Due to this navigation, interest in spatial reasoning develops at an early age. 1,872 preschool-1st grade children demonstrated high spatial reasoning ability (Zhong, 2009). Gersmehl, \& Gersmehl (2007) in their review concluded that children's spatial reasoning functions as early as three years (Nardini et al., 2006; Blaut et al, 2003 and Huttenlocher, et al., 1999). Blaut et al, (2003) proved that this spatial reasoning function is universal, ecological and cultural. The universality of spatial reasoning is highlighted in Pellicano, Rhodes \& Peters (2006) that map-like modelling is used by nearly all cultures Blaut et al. (2003) reported that 4 year olds in Durban South Africa were able to read aerial photographs of their surroundings. Generally, underestimating young children's ability to learn mathematics goes against their psychological development. Research has to focus on how to strengthen ways of developing these innate abilities further for future gains.

\section{Perceived mathematics ability differences}

Lee and Ginsburg (2009) argue that teachers believe that only certain children have ability to learn mathematics. Izard et al (2009) investigated whether children have to come from specific cultures, or groups to possess abstract numerical representations. The findings showed that new-born babies have a sense of numbers that is characterized by ratio dependence and this number sense "increase[s] in precision over the course of human development" (p. 10384).

\section{Literacy and mathematics}

In support Lee and Ginsburg's (2010) claim that mathematics ability in early years predicts academic success at a later stage a meta-analysis of six longitudinal studies indicated that reading and mathematical abilities are equally important in predicting later reading and mathematics achievement (Duncan et al., 2007). In this metaanalysis, it is clear that "school entry reading skills predict subsequent reading achievement better than subsequent mathematics achievement, just as early math skills are more predictive of later math than reading achievement" (p.1437). This study further showed that knowledge of numbers and ordinality showed more strength in predicting later learning with an effect size of .34, while language and reading skills, such as vocabulary and word knowledge, indicated lesser strength in predicting later learning with an effect size of .17 (Duncan et al., 2007). Hence, the National Research Council (2009) in the US common core standards state that:

Mathematics experiences in early childhood settings should concentrate on (1) number (which includes whole number, operations, and relations) and (2) geometry, spatial relations, and measurement, with more mathematics learning time devoted to number than to other topics. Mathematical process goals should be integrated in these content areas (p.3). 
Young children's mathematical development has been acknowledged as a critical step towards preparing them for successful gains in their learning experiences and future learning.

\section{Role of the educator in young children's learning of mathematics}

Kirova and Bhargava (2002) conducted a qualitative inquiry investigating the role played by a teacher in guiding mathematical development of young children through play using everyday materials. Their findings highlighted professional growth as the critical area teachers need to attain in order to guide children's understanding of mathematical concepts. The three areas highlighted by this study are:

- The ability to recognize children's demonstrated understanding of mathematical concepts

- The ability to use mathematical language to guide their progress from behavioural to representational understanding of mathematical concepts

- The ability to assess systematically children's understanding of mathematical concepts

The first critical area relates back to the children's innate abilities as they are what children bring to the pre-school classroom. Practitioners need to remain aware of the thinking levels children enter his/her classroom with. For example, from activity based research funded by NSF conducted by the Regents' Centre for Early childhood at the University of Northern lowa a three year old boy (Tyla) was playing with drums making some music. When I joined him I realized he was counting as he bit the drum and his sequence was 1, 2, 4, 6. He called each number with the bit of the drum. This could indicate that he was doing one-to-one correspondence. However, the sequence was mixed. The role of the teacher in such a case is to recognize where Tyla is with the concept of counting. What does Tyla know? Where does he fall short in the knowledge he demonstrates? In this case find out if Tyla is counting or singing by saying 1, 2, 4, 6 by playing along and introducing other objects and ask him to count them even the drum sticks he is using to bit the drum then depending on his response you might establish that he knows that a number goes with a bit or an object (one-to-one correspondence). Therefore he falls short of using correct number sequence, instead of 1, 2, 3, 4 Tyla knows 1, 2, 5, 6.

According to Lee and Ginsburg (2010) children learn to use the language of mathematics at the age of two by memorizing the first 10 counting words. These counting words are "essentially nonsense syllables with no underlying structure or meaning" (p. 39). Therefore, Tyla's counting words have no meaning, but his use of a bit that matches a number word indicates his understanding of matching a counting word with a bit. Therefore, the role of his teacher would be to develop the concept of one-to-one correspondence further by developing the verbal counting sequence first. In doing so the teacher needs to find a path towards development of correct 
number sequence. Clements and Sarama (2009:1) suggest learning trajectories for developing young children's mathematics development; these learning trajectories have three parts; 1) a mathematical goal, 2) a developmental path along which children develop to reach that goal, and 3) a set of instructional activities, or tasks, matched to each of the levels of thinking in that path that help children develop higher levels of thinking. These learning trajectories then guide teacher development for teachers of young children.

\section{A mathematical goal}

According to Clements and Sarama (2009), a mathematical goal refers to the 'big ideas' of mathematics. In describing big ideas Clements and Sarama (2004) express the centrality of these ideas to mathematics; they include mathematical skills, clusters of mathematical concepts that are lucid, "consistent with children's thinking, and generative of future learning" (Clements and Sarama, 2009, 1). For example, in Tyla's case, mentioned previously, the big idea is meaningful counting. As it is in the story there are many skills and concepts he needs to attain towards becoming a meaningful counter, the first will be verbal counting sequence followed by many more hence the cluster of mathematical concepts that generate future learning are part of the description of big ideas.

In order to achieve learning of these mathematical concepts by young children, Clements (2001: 270) asserts that "quality preschool mathematics is not elementary arithmetic pushed onto younger children; instead, it invites children to experience mathematics as they play in, describe, and think about their world". Therefore, mathematical learning for young children is about their own world, not the adult world. Adults have to adjust themselves into thinking like children for them to be able to nurture their mathematical development.

\section{Developmental progression}

Nurturing of mathematics development for young children should be at the level of the children. This acknowledgement of developmental appropriate experiences guides strategies used in mediating mathematics to young children. Thus, the developmental progression has two main paths: the paths for learning and the paths for teaching.

\section{The paths of learning}

Thinking levels of children are vital at this point. Children are considered the starting point for the learning. Going back to Tyla's story, a developmental path that will lead him to be able to count in a socially constructed way has to be drawn. With children's ideas and interpretation in mind, Tyla's developmental path has to acknowledge that he is playing with drums and using counting words at the bit he makes on the drum. Tyla requires a teacher that will recognize his interest in the drum playing and use this play purposefully. Clements and Sarama (2009: 3) place Tyla at the recite thinking 
level because "he counts verbally with separate counting words not necessarily in the correct order". At this level using the drum play with Tyla associating it as he did with number words in correct sequence will be the beginning of the learning path (Clements and Sarama, 2009).

\section{The paths for teaching}

Extending Tyla's play into repeated activities in different contexts will provide him with tasks that will nurture his development towards becoming a counter. These tasks are the paths for teaching that are matched at each thinking level of the child. Clements and Sarama (2009) have developed tasks for each development. It is important to note that the ages they allocated at each level are approximated depending on children's experiences. Also as Tyla's story indicated that a child can be in more than one level at the same time. Therefore, learning is not always linear; Siegler (2007) asserts that it varies within children and amongst children. Developing these tasks is not easy, but challenging instead. Tyla might not be able to do one-to-one correspondence on using counters for counting. Therefore, teachers need to understand this variability and carefully plan with no high expectations on the outcomes. Clements and Sarama learning trajectories give a foundation for teacher development on teaching mathematics and for research to assess how children go through the developmental progressions in order to support or refute Siegler's view.

\section{Conclusion}

Early childhood mathematics research from other countries played a significant role in improving quality mathematics practices, policy formulation and curriculum development. South African research needs to be rigorous in enabling the realization of the NIP on mathematics stimulation. Literature proves the impact of pre-school quality mathematics, however in implementing such ideas South Africa needs to consider its unique challenges. As Richter et al (2012) suggested access to ECD centres has to improve; home-based stimulation needs to be part of the NIP and empowering of local government in delivering ECD services have to be considered. Therefore this paper argues for mathematics interventions that are able to equip the mother/ grandmother/care giver who is taking care of kids at home as well as those who are in centres through local government. Longitudinal studies on quality mathematics interventions need to inform stakeholders about the impact in schooling experiences, college experiences and labour market. Through these tracking longitudinal studies the private sector and the responsible departments would support early childhood mathematics stimulation with empirical evidence and gain confidence in promoting and educating the community on the importance of mathematics stimulation in the ECD. 


\section{References}

Adler, J. (2001). Teaching mathematics in multilingual classrooms. Dodrecht: Kluwer

Becker, B. E.; \& Luther, S. S. (2002). Social-Emotional Factors Affecting Achievement Outcomes Among Disadvantage Students: Closing the Achievement Gap. Educational Psychologist, 37(4), 197-214.

Biersteker, L.; \& Dawes, A. (2008). Scaling up early Childhood Development (ECD) (0-4 Years) in South Africa . Case Studies: ECD Services in Brazil and the Philippines. A Summary Report, HSRC.

Blaut, J. M., Stea, D., Spencer, C., and Blades, M. (2003). Mapping as a Cultural and Cognitive Universal. Annals of the Association of American Geographers, 93(1), 165- 185 .

Bowman, B.T., Donovan, M. S., \& Burns, M.S. (Eds.). (2001). Eager to learn: Educating our pre-schoolers. Washington, DC: National Academy Press.

Brooker, L. (2011). Taking children seriously: An alternative agenda for research? Journal of Early Childhood Research, 9(2), 137-149.

Chaiklin, S. (2003). The Zone of Proximal Development in Vygotsky's analysis of Learning and Instruction. In Vygotsky educational theory in cultural context, ed. A. Kozulin, B. Gindis, V. Ageyev, and S. Miller., 39-64. Cambridge: Cambridge University Press.

Clements D. H., Battista, M.T., Sarama, J., Swaminathan, S., \& McMillen, S. (1997). Student's development of length measurement concepts in a Logo-based unit on geometric paths. Journal for Research in Mathematics Education, 28(1), 70-95.

Clements, D. H. (2001). Mathematics in the Preschool. Retrieved by 30 June 2011 at www.nctm.org. Teaching Children Mathematics. The National Council of Teachers of Mathematics Inc, 270-275.

Clements, D. H., \& Stephen, M. (2004). Measurement in the pre-K to grade 2 mathematics. In D. H. Clements, J. Sarama, \& A. DiBiase (Eds.), Engaging young children in mathematics: Standards for early childhood mathematics education, 299-317. Mahwah, NJ: Erlbaum.

Clements, D. H., \& Sarama, J. (Eds.) (2004). Hypothetical learning trajectories. Mathematical Thinking and Learning [Special issue], 6(2).

Clements, D. H., \& Sarama, J. (2007). Effects of a Preschool Mathematics Curriculum: Summative Research on the Building Blocks Project. Journal for Research in Mathematics Education, 38(2), 136-163.

Clements, D. H., Wilson, D. C., \& Sarama, J. (2004). Young children's composition of geometric figures: A learning trajectory. Mathematical Thinking and Learning, 6(2), 163-184.

Clements, D. H., \& Sarama, J. (2009). Learning and teaching early math: The learning trajectories approach. New York: Routledge.

Clements, D. H., \& Sarama, J. (2009). Learning trajectories in early mathematicssequences of acquisition and teaching. Encyclopedia of Language and Literacy Development, 1-7. London, ON: Canadian Language and Literacy Research 
Network. Retrieved by 19 October 2011 from http://iteracyencyclopedia.ca/pdfs/ topic.php?topld=270.

Condry, K. F. \& Spelke, E. S. (2008). The development of language and abstract concepts: The case of natural number. Journal of Experimental Psychology: General, 137, 22- 38.

Denton, K., \& West, J. (2002). Children's reading and mathematics achievement in kindergarten and first grade. Retrieved by 29 June 2011 from http://nces.ed.gov/ pubsearch/pubsinfo.asp?pubid=2002125. National Center for Education Statistics

DeVries, R. \& Sales, C. (2011). Ramps \& Pathways: A constructivist approach to physics with young children. Washington DC: NAEYC

Donato, R. and D. Maccormick. (1994). A Sociocultural Perspective on Language Learning Strategies: The Role of Mediation. The Modern Language Journal, 78(4), 453-464.

Duncan, G. J., Claessens, A., Huston, A. C., Pagani, L. S., Engel, M., Sexton, H., Dowsett, C.J., Magnuson, K., Klebanov, P., Feinstein, L., Brooks-Gunn, J., \& Duckworth, K. (2007). School Readiness and Later Achievement, Developmental Psychology, 43(6), 1428-1446.

Ehrlich, S. B., Levin, S. C., and Goldin-Meadow, S. (2006). Importance of Gesture in Children's Spatial reasoning. Developmental Psychology, 42(6), 1259-1268.

Freudenthal, H. (1973). Mathematics as an educational task. Dordrecht: Kluwer Academic Publishers.

Gersmehl, P. J., and Gersmehl, C. A. (2007). Spatial Thinking by Young Children: Neurologic Evidence for Early Development and "Educability", Journal of Geography, 106, 186-191.

Gilmore, C.K., \& Spelke, E. S. (2008). Children's understanding of the relationship between addition and subtraction. Cognition, 107, 932-945.

Ginsburg, H. P., Cannon, J., Eisenband, J. G., \& Pappas,S. (2006). Mathematical thinking and learning. In K.McCartney \& D. Phillips (Eds.), Handbook of Early Child Development (pp. 208-229). Oxford, England:Blackwell.

Hoppenbrouwer, E. M. (2011). Introducing a child-centered numeracy play-center intervention in three rural preschools in Dennilton, South Africa. Thesis submitted for fulfillment of a Master Social Education and Youth Policy Specialization Education, Youth and International Humanitarian Cooperation and Aid. University Utrecht Faculty Social Sciences, Department Educational Science.

Hutchinson, E., \& Pournara, G. (2011). Preschool children's Mathematical understanding. South African Journal of Childhood Education, 1(2), 92-111.

Huttenlocher, J., Newcombe, N., and Vasilyeva, M. (1999). Spatial scaling in young children. Psychological Science, 10(5), 393-398.

Hyde, D. C., \& Spelke, E. S. (2010). Neural signatures of number processing in human infants: evidence for two core systems underlying numerical cognition. Developmental Science, 1-12. 
Izard, V., Sann, C., Spelke, E. S., \& Streri, A. (2009). New-born infants perceive abstract numbers. Charles R. Gallistel (Ed), Proceedings of the National Academy of Science of the United States of America, 16(25), 10382-10385.

Judge, S., Pucket, K., \& Bell, S. M. (2006). Closing the digital divide: Update from the Early Childhood Longitudinal Study. The Journal of the Educational Research, 100(1), 52-60. doi:103200/JOER100.1.52-60.

Kamii, C. \& DeClark, G. (1985). Young children reinvent arithmetic: Implication of Piaget's theory. New York: Teachers College Press

Kamii, C. (2000). Young Children Reinvent Arithmetic. 2nd ed. New York: Teachers College Press.

Kamii, C, (2011, April). Key note address. National Council of Teachers of Mathematics Annual meeting, Indianapolis, Indiana.

Kirova, A., \& Bhargava, A. (2002). Learning to Guide Preschool Children's Mathematical Understanding: A Teacher's Professional Growth. Early Childhood Research and Practice, 4(1), 1-20.

Kozulin, A. (2003). Psychological tools and mediated learning. In Vygotsky educational theory in cultural context, ed. A. Kozulin, A., B. Gindis, V. Ageyev, and S. Miller, 1538. Cambridge: Cambridge University Press.

Lee, J. \& Ginsburg, H. P. (2009). Early childhood teachers' misconceptions about mathematics education for young children in the United States. Australasian Journal of Early Childhood, 34(4), 37-45.

Lu, J. (2001). The study of several of cognitive development. In Contemporary Chinese psychology, 259-264. Beijing: Beijing Normal University Press.

McCrink, K., \& Spelke, E. S. (2010). Core Multiplication in Childhood. Cognition, 116, 204- 216.

Mji. A. \& Makgato. M. (2006). Factors associated with high school learners' performance: a spotlight on mathematics and physical science. South African Journal of Education, 26(2), 253-266.

National Research Council (2009). 2010 Common Core State Standards in Mathematics. Retrieved by October 19, 2011 at http://corestandards.org/

Nardini, M.,burgess, n., Breckenridge, K., and Atkinson, J. (2006). Differential developmental trajectories for egocentric, environmental and intrinsic frames of reference in spatial memory. Cognition, 101, 153-172.

Pellicano, E., Rhodes, G., and Peters, M. (2006). Are pre-schoolers sensitive to configural information in faces? Developmental Science, 9(3), 270-277.

Penn, H. (2008). Early Childhood Education and Care in Southern Africa. A perspective report. CfBT Education Trust. Retrieved by 16 June 2011 at http://www.cfbt.com

Piaget, J. (1964). Development and learning. In Piaget rediscovered: A report of the Conference on Cognitive Studies and Curriculum Development, eds. R.E. Ripple \& V. N. Rockcastle, 7-20. Ithaca, NY: Cornell University Press. 
Piaget, J. \& Inhelder, B. (1969). The Psychology of the Child. Paris, Denoel.

Richter, L., Biersteker, L., Burns, J., Desmond, C., Feza, N., , , Martin, P., Saloojee, H. \& Slemming, W. (2012). Diagnostic review of early childhood development. (Commissioned by the Presidency, March).

Setati, M., \& Adler, J. (2001). Between languages and discourses: Language practices in primary multilingual mathematics classroom in South Africa. Educational Studies in Mathematics, 43, 243-269.

Siegler, R. S. (2007). Cognitive Variability. Developmental Psychology, 10(1), 104-109.

Siraj-Blarchford, I., Sylvia, K., Muttock, S., Gilden, R., \& Bell, D. (2002). Researching Effective Pedagogy in the Early Years (REPEY Report). London: DfES Research Report 356.

Slovin, H., Venenciano, L., \& DaSilva, M. (2008, April). How does classroom communication measure up? Getting kids to ask the important questions. Presented at the National Council of Teachers of Mathematics Annual Meeting, Salt Lake City, UT.

Starkey, P., Klein, A., \& Wakeley, A. (2004). Enhancing young children's mathematical knowledge through a pre-kindergarten mathematics intervention. Early Childhood Research Quarterly, 19, 99-120.

Starkey, P., \& Klein, A. (2008). Sociocultural Influences on Young Children's Mathematical Knowledge: Contemporary Perspectives on Mathematics in Early Childhood Education. Charlotte, NC: Information Age.

Spelke, E.S., Gilmore, C. K., \& McCarthy, S. (2011). Kindergarten children's sensitivity to geometry in maps. Developmental Science, 14(4), 809-821.

Spelke, E.S. (2011). Natural number and natural geometry. In E. Brannon \& S. Dehaene (Eds.), Space, Time and Number in the Brain: Searching for the Foundations of Mathematical Thought, 287-317. Attention \& Performance XXIV, Oxford University Press.

Sylva, K., Melhuish, E., Sammons, P., Siraj-Blatchford, I and Taggart, B. (2004). Final Report, Effective Provision of Preschool Education (EPPE) Project. London: Institute of Education.

UNICEF (2005). National Integrated Plan for Early Childhood Development in South Africa 2005-2010. Pretoria

Van der Sandt, S. \& Niewoudt, H. (2003). Grade 7 teachers' and prospective teachers' content knowledge of geometry. South African Journal of Education, 23(3), 199- 205.

Van Hiele, P. M. (1986). Structure and insight: A theory of mathematics education. Orlando, FL: Academic Press.

Vygotsky, L. S. (1978). Mind in society: The development of higher psychological process. Cambridge, MA: Harvard University Press. 
Wang, F. R., \& Spelke, E. S. (2002). Human spatial representation: insights from animals. Trends in Cognitive Sciences, 6(9), 376-382.

White, H. R. (1987). Longitudinal stability and dimensional structure of the problem drinking in adolescence. J Stud Alcohol, 48, 541-550 .

Wright, R. J., Martland, J. \& Stafford, A.K. (2000). Early Numeracy: Assessment for Teaching and Intervention. London, Chapman.

Young-Loveridge, J. (2004). Effects on early numeracy of a program using number books and games. Early Childhood Research Quarterly, 19, 82-98.

Zhong, T. (2009). A Study of Children's Spatial Reasoning and Quantitative Reasoning Abilities. Journal of Mathematics Education, 2(2), 80-93. 